\title{
Article \\ Oil and Flower Production in Rosa damascena trigintipetala Dieck under Salinity Stress in Taif Region, Saudi Arabia
}

\author{
Mohamed E. El-Sharnouby ${ }^{1, *}$, Metwally M. Montaser $^{2}\left(\mathbb{D}\right.$ and Sliai M. Abdallah ${ }^{3}$ \\ 1 Department of Biotechnology, College of Science, Taif University, P.O. Box 11099, Taif 21944, Saudi Arabia \\ 2 Science and Technology Department, University College of Ranyah, Taif University, \\ Ranyah 21975, Saudi Arabia; m.montaser@tu.edu.sa \\ 3 Department of Biology, Turabah University College, Taif University, Taif 21944, Saudi Arabia; \\ a.sliai@tu.edu.sa \\ * Correspondence: m.sharnouby@tu.edu.sa
}

Citation: El-Sharnouby, M.E.;

Montaser, M.M.; Abdallah, S.M. Oil and Flower Production in Rosa damascena trigintipetala Dieck under Salinity Stress in Taif Region, Saudi Arabia. Sustainability 2021, 13, 4547. https://doi.org/10.3390/su13084547

Academic Editor: Christopher Robin Bryant

Received: 24 February 2021

Accepted: 16 April 2021

Published: 19 April 2021

Publisher's Note: MDPI stays neutral with regard to jurisdictional claims in published maps and institutional affiliations.

Copyright: (c) 2021 by the authors. Licensee MDPI, Basel, Switzerland. This article is an open access article distributed under the terms and conditions of the Creative Commons Attribution (CC BY) license (https:/ / creativecommons.org/licenses/by/ $4.0 /)$.

\begin{abstract}
The flower industry depends on oil and fragrance, which is addressed in the current work. Different concentrations of $\mathrm{NaCl}(0,250,500,1000$, and $1500 \mathrm{ppm})$ were applied to Taif rose plants (Rosa damascena var. trigintipetala Dieck) to evaluate their effects on growth and essential oil content. Results clearly indicated the highest survival percentage $(98.3 \%)$ was seen in untreated plants compared to plants under salinity stress. Moreover, increasing the $\mathrm{NaCl}$ levels induced an adverse effect on the growth parameters of Taif rose plants, while some essential oil contents were increased to the maximum degree of their tolerance to salinity stress. The extracted essential oils were analyzed using GC/MS. The essential oils of Taif rose plants treated with $500 \mathrm{ppm} \mathrm{NaCl}$ recorded the highest values of citronellol, geraniol and phenylethyl alcohol contents (16.56, 8.67 and 9.87\%), respectively. $\mathrm{NaCl}$ at $250 \mathrm{ppm}$ produced the highest values of heneicosane $(13.12 \%)$, and then decreased to the lowest value $(7.79 \%$ ) with the increase of $\mathrm{NaCl}$ to $1500 \mathrm{NaCl}$, compared to the control and other $\mathrm{NaCl}$ levels. The current results could highlight the impact of salinity stress on Rosa damascena Miller var. trigintipetala Dieck for better economic and industrial applications.
\end{abstract}

Keywords: citronellol; geraniol; $\mathrm{NaCl}$; survival; Taif rose plants

\section{Introduction}

Globally, salinization is a major challenge to sustainable agricultural production and food security. Mismanagement of agricultural lands and overexploitation of water resources in arid climates have been highlighted as some of the major causes of soil salinization [1]. In addition to reducing net arable lands, soil salinization has serious implications for food security and the livelihoods of farmers, potentially impacting the regional and national economy [2]. Salinity is one of the main limiting factors for agricultural and natural production. Plants exposed to salinity at high levels induce more biochemical and physiological changes, leading to modifications in the function of cell membranes [3]. High salt content in irrigating water causes a reduction in plant growth and crop yields $[4,5]$.

Salinity stress because of excessive $\mathrm{Cl}-$ and $\mathrm{Na}+$ ions reduce plant growth, and has an adverse effect on plant physiology [6]. There are many plants tolerant to $\mathrm{NaCl}$ that can survive and adapt to high salinity, and induce physiological and biochemical changes [7]. Zhang et al. [8] studied the physiological responses of Populus sp. plants to different salinity levels. Chen et al. reported the use of MS/MS technology in the evaluation of salt-stress tolerance on Apocynum venetum L. plants for Chinese medicine, to get a total of 43 bioactive contents in response to salinity [9], while others recently reported the salinity impact on fatty acid composition in different aromatic plants, such as coriander, sweet marjoram, and sweet basil [10-12]. 
The majority of recent research on salt tolerance in plants focuses on determining the genes involved in the molecular mechanisms of tolerance, and some use transgenic plants in order to get a better response to salinity [13].

Recently, many studies were conducted to detect the effects of abiotic factors on the production of essential oil contents in aromatic species [14]. Lui et al. [15] used GCMS analysis and compared the phytochemical characteristics of both Rosa roxburghii and $R$. sterilis. They reported 91 different components between $R$. roxburghii and $R$. sterilis fruit [15]. Others reported the major essential oil content to be nonadecane (15\%), citronellol $(13 \%)$, heneicosane $(17 \%)$, and geraniol $(9 \%)$. However, the main compounds of the essential oils were nonadecene (4-4.55\%), $\beta$-citronellol (30-31\%), trans-geraniol (20-21\%), n-heneicosane (8-9\%), and phenylethyl alcohol (4-4.16\%) [16]. Ryu's group investigated the volatile compositions of 12 rose (Rosa hybrida) flower-color mutant variants and their original cultivars [17]. It is worth stating that plants grown under open sun with a black polyethylene mulch produced a good quality of damask rose [18].

Roses are one of the most important floricultural crops, and their essential oils are used for cosmetics and aromatherapy. Rosa damascena Miller var. trigintipetala Dieck is considered one of the best species for producing rose oil. It is commonly known as the damask rose, and is considered the most important commercial crop in the Taif region [11]. Saudi Arabia is flourishing in the Taif region through flower cultivation [12]. Kürkçüoglu et al. (2013) reported that the fresh flowers of Rosa damascena Miller var. trigintipetala Dieck cultivated in the Taif region are the source of Taif rose oil [19]. Taif roses have been processed into attar of roses and rose water for the past two centuries. Taif rose oil and rose water have become important and commercially valuable products, and the oil can also help in the treatment of depression [20].

The quality of the essential oil of the damask rose is due to the high percentage of monoterpene alcohols such as citronellol, phenyl ethyl alcohol, hydrocarbons, and nonadecene. The growth and yield of damask roses are affected by many agronomic factors [21].

The present work was designed to evaluate the tolerance of Taif rose plants to different concentrations of $\mathrm{NaCl}$, considering plant growth and the essential oil content of Taif rose plants.

\section{Materials and Methods}

Experiments were carried out at the biotechnology department of the Faculty of Science, Taif University, during 2020. The study investigated the growth of Taif rose plants (Rosa damascena trigintipetala Dieck) cultured in the Taif region for 6 months at different salinity treatment levels. Rose plant leaves were taken to determine growth parameters regarding the number of leaves, number of flowers, height of plants, survival percentage, and essential oil content.

\subsection{Experiment Design}

Nodes of the Taif rose plant (Rosa damascena trigintipetala Dieck) were cultured in plastic pots (10 cm height, $82 \mathrm{~cm}$ top circumference, and $70 \mathrm{~cm}$ bottom circumference), containing $2.5 \mathrm{~kg}$ of a mix of sand and peat moss $(1: 1)\left(\mathrm{ARBER}^{\circledR}\right.$ Horticulture, Italy). The plants were cultured at five salinity levels $(0,250,500,1000$, and $1500 \mathrm{ppm} \mathrm{NaCl})$. Fifty plants were randomly divided into 5 groups of 10 pots each (1 plant/pot) according to Attia et al. [22], with modifications. Each treatment was applied to a group of plants (10 plants/group). The plants were irrigated once $(300 \mathrm{~mL}$ tape water per pot) and then treated with saline water every three days. Cultures were kept in an open field during the summer of 2019 at Taif City, KSA.

\subsection{Measurement of Growth Parameters}

After 6 months of Taif rose plant (Rosa damascena trigintipetala Dieck) cultivation, stress tolerance was evaluated based on morphological parameters such as plant height $(\mathrm{cm})$, 
number of leaves (leaf/plant) and flowers (rose/plant), and plant survival (live plant/total 250 plants) was recorded.

\subsection{Extraction Method of Essential Oil}

Twenty mg of rose essential oil was extracted from 100 gm flower samples, and dissolved in $1 \mathrm{~mL} \mathrm{~N}$ - hexane for $4 \mathrm{~h}$. Triplicates were used for each sample. Essential oil samples used for the GC/MS analysis were dissolved in dichloromethane according to Xiao et al. [23].

\subsection{Gas Chromatography of Taif Rose Essential Oil}

The analysis of the samples was performed using a Varian GC-MS system (Model Varian CP 3800, Varian Saturn 2200) at $70 \mathrm{e} \mathrm{V}, 250{ }^{\circ} \mathrm{C}$, using helium as the carrier gas (flow rate of $1 \mathrm{~mL} / \mathrm{min}$ ). The oven temperature was programmed for $5 \mathrm{~min}$ at $260{ }^{\circ} \mathrm{C}$. Identification of components as concrete and absolute oils was based on matching with Wiley and the NIST electronic library.

\subsection{Statistical Analysis}

The significant difference between factors was ascertained. Leven's test was used to determine data homogeneity, followed by the least significant difference with Post-Hoc one-way ANOVA (analysis of variance) using SPSS statistical software (v.20). Each group was represented by 3 plants per pot (10 pots per group).

\section{Results}

\subsection{Effect of Salinity Stress on Plant Survival Percentage}

Growth and survival percentages of the Taif rose plant (Rosa damascena trigintipetala Dieck) decreased with increasing levels of $\mathrm{NaCl}$ stress, as compared with the control. Concerning the response of survival percentage due to $\mathrm{NaCl}$ treatments, the results clearly indicated that the highest survival percentage (98.3\%) occurred in the control group (Table 1 ).

Table 1. Effect of due salinity stress on plant survival rate $(\%=100 \times$ survived plants $/$ total plants $)$.

\begin{tabular}{cccccc}
\hline \multirow{2}{*}{ Parameters } & \multicolumn{5}{c}{ NaCl Conc (x PPM) } \\
\cline { 2 - 6 } & $\mathbf{0}$ & $\mathbf{2 5 0}$ & $\mathbf{5 0 0}$ & $\mathbf{1 0 0 0}$ & $\mathbf{1 5 0 0}$ \\
\hline$\%$ Survived plants & $98.3 \pm 0.55^{\mathrm{a}}$ & $83.5 \pm 0.85^{\mathrm{b}}$ & $80.3 \pm 0.49^{\mathrm{b}}$ & $62.2 \pm 0.78^{\mathrm{c}}$ & $55.3 \pm 2.17^{\mathrm{d}}$ \\
\hline
\end{tabular}

Data are expressed in group mean \pm SE. Data with different letters show statistically significant $(p \leq 0.05)$ difference. Least significant difference $(\mathrm{LSD})=1.62$.

Culturing the Taif rose explants in pots containing $1500 \mathrm{ppm} \mathrm{NaCl}$ reduced the survival percentage to the minimum value (55.3\%). The other treatments recorded a decrease in survival percentage with the increase in $\mathrm{NaCl}$ levels. However, the differences among all groups were statistically significant $(p \leq 0.05)$, except between the 250 and 500 ppm groups. The value of the least significant difference was 1.62 .

\subsection{Effect of Salinity Stress on Plant Height}

Table 2 shows that increased $\mathrm{NaCl}$ levels significantly $(p \leq 0.05)$ reduced plant height (Table 2). Data also showed that $1500 \mathrm{ppm}$ of $\mathrm{NaCl}$ gave the shortest shoots $(38.9 \pm 1.86 \mathrm{~cm})$, whereas the control plants recorded the longest shoot length $(72.5 \pm 1.18 \mathrm{~cm})$. Culturing the Taif rose explants at different concentrations of $\mathrm{NaCl}$ significantly $(p \leq 0.05)$ decreased the plant height compared with control. The differences among group means were statistically significant, with 1.81 the least significant difference value. 
Table 2. Effect of salinity stress on plant parameters (plant height, number of leaves, and number of flowers).

\begin{tabular}{cccc}
\hline \multirow{2}{*}{ NaCl Conc (x PPM) } & \multicolumn{3}{c}{ Plant Parameters } \\
\cline { 2 - 4 } & Plant Height & Number of Leaves & Number of Flower \\
\hline 0 & $72.5 \pm 1.18^{\mathrm{a}}$ & $55.6 \pm 0.67^{\mathrm{a}}$ & $4.5 \pm 0.32^{\mathrm{a}}$ \\
250 & $64.2 \pm 1.16^{\mathrm{b}}$ & $41.6 \pm 0.48^{\mathrm{b}}$ & $3.4 \pm 0.15^{\mathrm{b}, \mathrm{c}, \mathrm{d}}$ \\
500 & $56.5 \pm 0.35^{\mathrm{c}}$ & $38.4 \pm 0.12^{\mathrm{c}}$ & $3.2 \pm 0.07^{\mathrm{c}}$ \\
1000 & $47.7 \pm 1.39^{\mathrm{d}}$ & $28.5 \pm 0.50^{\mathrm{d}}$ & $3.6 \pm 0.09^{\mathrm{d}}$ \\
1500 & $38.9 \pm 1.86^{\mathrm{e}}$ & $25.5 \pm 0.31^{\mathrm{e}}$ & $2.7 \pm 0.12^{\mathrm{e}}$ \\
\hline LSD & 1.81 & 0.64 & 0.20
\end{tabular}

Data are expressed in group mean \pm SE. Data in the same column annotated with different letters show statistically significant $(p \leq 0.05)$ differences. Least significant difference (LSD).

\subsection{Effect of Salinity Stress on Number of Leaves/Plant}

Regarding the number of leaves (Table 2), the untreated Taif rose plants produced a significantly $(p \leq 0.05)$ greater number of leaves per explant $(55.6 \pm 0.67)$ than with $\mathrm{NaCl}$ at all other concentrations. The averages of leaf numbers for salt concentrations (250, 500,1000 , and $1500 \mathrm{ppm}$ ) were $41.6,38.4,28.5$, and 25.5 leaves per plant, respectively. All $\mathrm{NaCl}$ treatment decreased the number of leaves compared with the control. The differences between group means were statistically significant, with 0.64 the least significant difference value.

\subsection{Effect of Salinity Stress on the Number of Flowers per Plant}

Table 2 shows that plants grown at $1500 \mathrm{ppm} \mathrm{NaCl}$ significantly $(p \leq 0.05)$ produced the least number of flowers $(2.7 \pm 0.12$ rose/plant). While untreated plants produced the highest number ( $4.5 \pm 0.32$ rose/plant), it was clear that different $\mathrm{NaCl}$ concentrations were more effective on growth parameters. The minimum flower number ( $3.2 \pm 0.07$ rose/plant) was in the case of the $500 \mathrm{ppm} \mathrm{NaCl}$ dose. The differences among the group means were statistically significant $(p \leq 0.05)$ except for the flower number $(3.4,3.2$, and 3.6 rose/plant) at $\mathrm{NaCl}$ treatment doses of 250,500, and $1000 \mathrm{ppm}$, respectively. The least significant difference between groups was 0.20 (Table 2).

\subsection{Gas Chromatography Analysis of Essential Oil Contents in Taif Rose Plants}

GC-MS analysis identified various compounds in Taif rose essential oils. The major components were identified and are listed in Figure 1. The total number of peaks were obtained from Taif rose plant leaves at A (0), B (250), and C (500) ppm NaCl, respectively, as illustrated in Figure 1.

Citronellol, geraniol, phenyl ethyl alcohol, nonadecene, and heneicosane were the major essential oil components of the Taif rose plant. Peaks in the different samples indicated that the plants grown under $500 \mathrm{ppm} \mathrm{NaCl}$ produced the highest contents of citronellol (16.56\%), geraniol (8.67\%) and phenyl ethyl alcohol $(9.87 \%)$. The data in Table 3 also showed that there was an increase in the nonadecene content in untreated plants, which gave the highest value $(8.13 \%)$ compared with the other $\mathrm{NaCl}$ levels. The heneicosane content increased with $250 \mathrm{ppm} \mathrm{NaCl}$ to the highest value and reached $13.12 \%$, then decreased with increasing $\mathrm{NaCl}$ treatments and reached the lowest value $(7.79 \%)$ with $1500 \mathrm{ppm} \mathrm{NaCl}$. These results mean that the Taif essential oil levels were increased under some salinity stress treatments. These results explain the finding that $\mathrm{NaCl}$ at $500 \mathrm{ppm}$ encouraged the cultured Taif rose plants to increase the citronellol, geraniol and phenyl ethyl alcohol contents (Table 3 and Figure 1). 


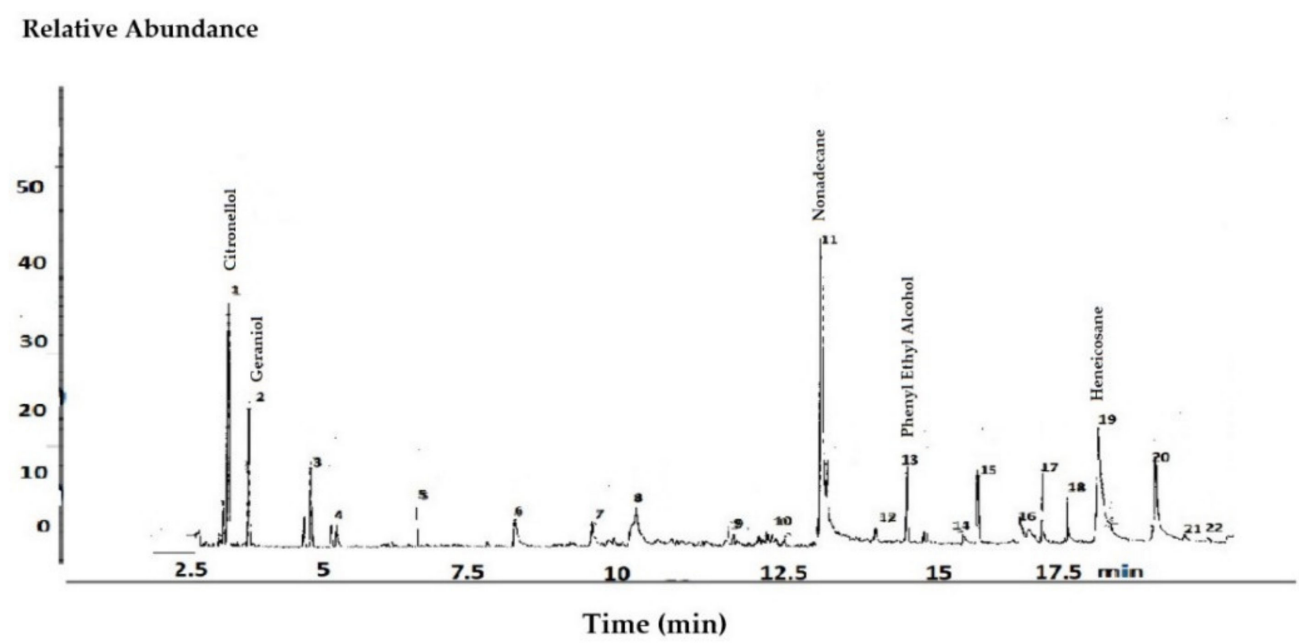

(A)

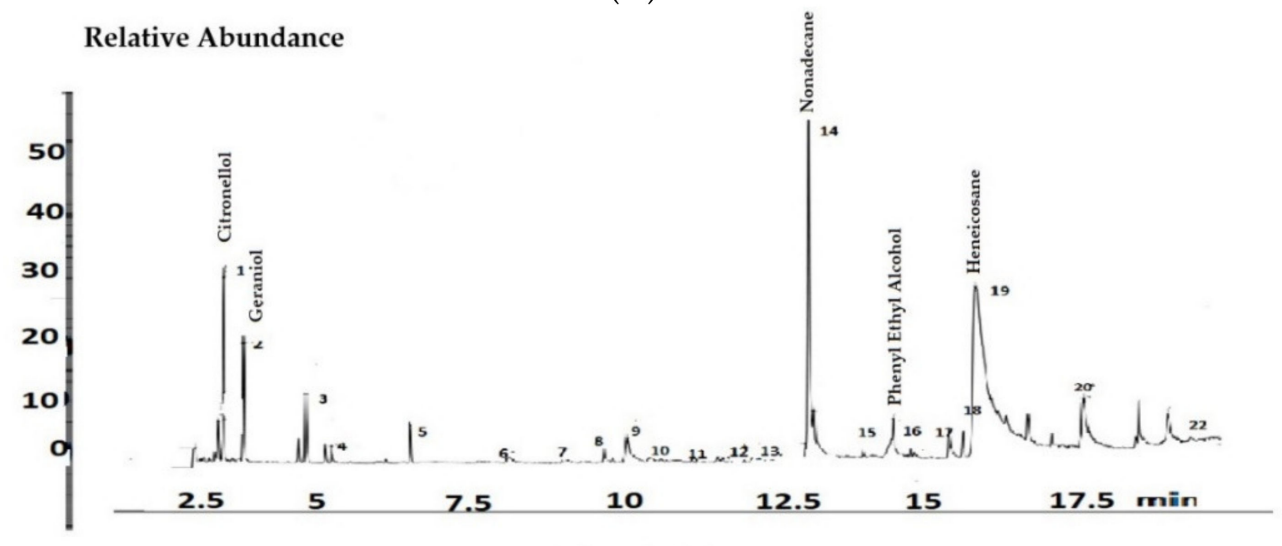

Time (min)

(B)

Relative Abundance

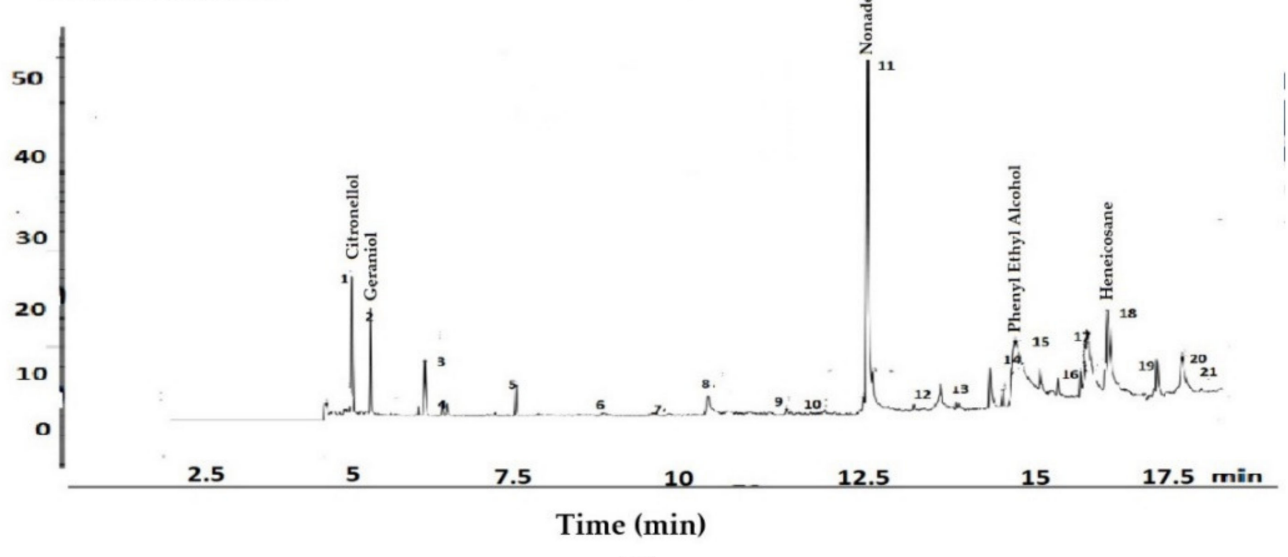

(C)

Figure 1. GC-MS chromatogram analysis of essential oil contents in Taif rose plants (Rosa damascena trigintipetala Dieck) grown under $\mathrm{NaCl}$ concentrations. (A) (0), (B) (250) and (C) (500) ppm NaCl. 
Table 3. Effect of salinity stress on rose essential oil.

\begin{tabular}{|c|c|c|c|c|c|}
\hline \multirow[b]{2}{*}{$\begin{array}{l}\text { NaCl Conc } \\
\text { (x PPM) }\end{array}$} & \multicolumn{5}{|c|}{ Essential Oil (\%) } \\
\hline & Citronellol & Geraniol & $\begin{array}{c}\text { Phenyl Ethyl } \\
\text { Alcohol }\end{array}$ & Nonadecane & Heneicosane \\
\hline 0 & $14.77 \pm 0.14^{\mathrm{a}}$ & $7.87 \pm 0.51^{\mathrm{a}}$ & $5.15 \pm 1.72^{\mathrm{a}}$ & $8.13 \pm 0.46^{\mathrm{a}}$ & $9.22 \pm 0.16^{\mathrm{a}}$ \\
\hline 250 & $10.26 \pm 0.45^{b}$ & $4.94 \pm 0.22^{b}$ & $5.15 \pm 0.23^{\mathrm{a}, \mathrm{b}}$ & $6.32 \pm 0.42^{b}$ & $13.12 \pm 0.07^{b}$ \\
\hline 500 & $16.56 \pm 0.34^{c}$ & $8.67 \pm 0.20^{a, c}$ & $9.87 \pm 0.07^{\mathrm{c}}$ & $3.23 \pm 0.13^{c}$ & $8.71 \pm 0.05^{\mathrm{a}, \mathrm{c}}$ \\
\hline 1000 & $15.39 \pm 0.41^{\mathrm{a}, \mathrm{c}, \mathrm{d}}$ & $6.55 \pm 0.32^{\mathrm{d}, \mathrm{e}}$ & $2.34 \pm 0.19^{\mathrm{a}, \mathrm{b}, \mathrm{d}}$ & $3.56 \pm 0.31^{c, d}$ & $8.54 \pm 0.31^{c, d}$ \\
\hline 1500 & $14.98 \pm 0.45^{\mathrm{a}, \mathrm{d}, \mathrm{e}}$ & $7.72 \pm 0.15^{\mathrm{a}, \mathrm{c}, \mathrm{e}}$ & $7.43 \pm 0.33^{b, c, e}$ & $3.51 \pm 0.29^{\mathrm{c}, \mathrm{d}, \mathrm{e}}$ & $7.79 \pm 0.30^{\mathrm{e}}$ \\
\hline LSD & 0.53 & 0.44 & 1.12 & 0.48 & 0.3 \\
\hline
\end{tabular}

Data are expressed as the mean of percentage at each group \pm SE. Data in the same column annotated with different letters have statistically significant $(p \leq 0.05)$ difference. Least significant difference (LSD).

\section{Discussion}

Roses are an important ornamental crop. The flower industry depends on flower color and fragrance [24]. The composition of the essential oils in flower extracts is an important determinant of oil quality [23].

The present study detected the effect of $\mathrm{NaCl}$ levels on the growth characteristics and essential oil content of Rosa damascena Miller var. trigintipetala Dieck, which is considered one of the best species for Taif rose oil production. This study confirmed that the growth characteristics of Rosa damascena Miller var. trigintipetala Dieck plants gradually increased in response to the elevation of $\mathrm{NaCl}$ levels. Meanwhile, a decrease in the number of leaves, survival percentage, and number of flowers as $\mathrm{NaCl}$ levels increased, compared with control plants, was in line with previous studies on the salinity of soil and irrigation water $[4,25]$. The results are also in good agreement with the results obtained by SánchezMontesinos et al., who demonstrated a reduction in plant growth of melon seedlings under saline stress conditions [26]. Plants under salt stress showed a decrease in shoot and root numbers, a delay in leaf appearance, and a reduction in leaf surface area and internode lengths [27].

Analysis of the oil samples using gas chromatography showed an increase in some essential oil contents in response to certain $\mathrm{NaCl}$ levels (500 ppm $\mathrm{NaCl}$ ), and increased metabolic activities. Our results are in agreement with previous tests on Taif rose oil to find the main constituents, $31.3 \%$ citronellol, $19.5 \%$ geraniol, and 10.3\% 5-methyl octadecane [11]. Others analyzed the components of damask rose essential oils and found oxygenated monoterpenes and aliphatic hydrocarbon as a major fraction. The major components were citronellol ( 35.5 to $49.2 \%$ ), trans-geraniol (12.6 to $18.4 \%$ ), nonadecane (8.9 to $15.1 \%$ ), heneicosane ( 3.8 to $8.7 \%$ ) and nonadecene (1.6 to 3.6\%) [18,28]. However, the essential oils represented in the present study were geraniol, citronellol and citronellyl formate. Current data were also in agreement with reports that demonstrated the major chemical composition of rose geranium oils to be citronellol [29], and that aliphatic hydrocarbons, aliphatic esters, and alcohols are major volatiles in all rose genotypes $[17,30]$. Previous reports explained that the effects of salinity stress levels, as well as the degree of tolerance in rose flowers, could be due to the induction of the specific enzymes involved in the biosynthesis of these compounds by salinity [31].

\section{Conclusions}

Plant growth and the quality of the essential oil from Rosa damascena Miller var. trigintipetala Dieck were assessed at different $\mathrm{NaCl}$ levels. An obvious decrease response in plant growth was currently recorded. Moreover, this may represent an effective method of improving and stimulating the quality of essential oil constituents including citronellol, geraniol, and phenyl ethyl alcohol from Rosa damascena Miller var. trigintipetala Dieck at some $\mathrm{NaCl}$ levels, especially 500 ppm. 
Chemical changes induced by salinity could reflect an adaptation response to this factor. In this case, exposing Taif rose plants to salinity stress may function as a potential technique that could increase essential oil production. An increase in Taif rose oil properties may be due to oil quality genetics rather than to environmental influences during plant growth. The current results could highlight the impact of salinity stress on Rosa damascena Miller var. trigintipetala Dieck to achieve better economic and industrial applications. It could also be applied to improving the yield of ornamental and other crops to be planted in the Taif region or other arid and semi-arid lands all over the kingdom for greater investment.

Author Contributions: Conceptualization, methodology, data curation, writing-original draft preparation, writing-review, editing: M.E.E.-S., M.M.M., and S.M.A.; funding acquisition: M.E.E.-S. All authors have read and agreed to the published version of the manuscript.

Funding: This research received no external funding.

Data Availability Statement: Not applicable.

Acknowledgments: This work was carried out using the facilities and materials at Taif University Researches Supporting Project number (TURSP-2020/139), Taif University, Taif, Saudi Arabia.

Conflicts of Interest: The authors declare no conflict of interest.

\section{References}

1. Kayode, O.T.; Aizebeokhai, A.P.; Odukoya, A.M. Soil salinity and its implications on sustainable agriculture in Southern and Northcentral States of Nigeria. IOP Conf. Ser. Earth Environ. Sci. 2021, 655, 012077. [CrossRef]

2. Gopalakrishnan, T.; Kumar, L. Linking Long-Term Changes in Soil Salinity to Paddy Land Abandonment in Jaffna Peninsula, Sri Lanka. Agriculture 2021, 11, 211. [CrossRef]

3. Taarit, M.B.; Msaada, K.; Hosni, K.; Marzouk, B. Changes in fatty acid and essential oil composition of sage (Salvia officinalis L.) leaves under $\mathrm{NaCl}$ stress. Food Chem. 2010, 119, 951-956. [CrossRef]

4. Qin, Y.; Druzhinina, I.S.; Pan, X.; Yuan, Z. Microbially Mediated Plant Salt Tolerance and Microbiome-based Solutions for Saline Agriculture. Biotechnol. Adv. 2016, 34, 1245-1259. [CrossRef]

5. Selvakumar, G.; Kim, K.; Hu, S.; Sa, T. Effect of Salinity on Plants and the Role of Arbuscular Mycorrhizal Fungi and Plant GrowthPromoting Rhizobacteria in Alleviation of Salt Stress; Springer: New York, NY, USA, 2014; pp. 115-144.

6. Yaish, M.W.; Al-Lawati, A.; Jana, G.A.; Patankar, H.V.; Glick, B.R. Impact of Soil Salinity on the Structure of the Bacterial Endophytic Community Identified from the Roots of Caliph Medic (Medicago truncatula). PLoS ONE 2016, 11, e0159007. [CrossRef]

7. Acosta-Motos, J.R.; Ortuño, M.F.; Bernal-Vicente, A.; Diaz-Vivancos, P.; Sanchez-Blanco, M.J.; Hernandez, J.A. Plant Responses to Salt Stress: Adaptive Mechanisms. Agronomy 2017, 7, 18. [CrossRef]

8. Zhang, X.; Liu, L.; Chen, B.; Qin, Z.; Xiao, Y.; Zhang, Y.; Yao, R.; Liu, H.; Yang, H. Progress in Understanding the Physiological and Molecular Responses of Populus to Salt Stress. Int. J. Mol. Sci. 2019, 20, 1312. [CrossRef] [PubMed]

9. Chen, C.; Wang, C.; Liu, Z.; Liu, X.; Zou, L.; Shi, J.; Chen, S.; Chen, J.; Tan, M. Variations in Physiology and Multiple Bioactive Constituents under Salt Stress Provide Insight into the Quality Evaluation of Apocyni Veneti Folium. Int. J. Mol. Sci. 2018, 19, 3042. [CrossRef] [PubMed]

10. Rebey, I.B.; Bourgou, S.; Rahali, F.Z.; Msaada, K.; Ksouri, R.; Marzouk, B. Relation between salt tolerance and biochemical changes in cumin ( Cuminum cyminum L.) seeds. J. Food Drug Anal. 2017, 25, 391-402. [CrossRef] [PubMed]

11. Bahaffi, S.O. Volatile oil composition of Taif rose. J. Saudi Chem. Soc. 2005, 9, 401-406.

12. Bazaid, S.A. Chemical composition of Rose hybrida essential oil as a function of location and storage in K.S.A. Am. Eur. J. Sust. Agric. 2009, 3, 24-28.

13. Hernández, J.A. Salinity Tolerance in Plants: Trends and Perspectives. Int. J. Mol. Sci. 2019, 20, 2408. [CrossRef] [PubMed]

14. Eiasu, B.; Steyn, J.; Soundy, P. Rose-scented geranium (Pelargonium capitatum $\times$ P. radens) growth and essential oil yield response to different soil water depletion regimes. Agric. Water Manag. 2009, 96, 991-1000. [CrossRef]

15. Liu, M.-H.; Zhang, Q.; Zhang, Y.-H.; Lu, X.-Y.; Fu, W.-M.; McPhee, D.J. Chemical Analysis of Dietary Constituents in Rosa roxburghii and Rosa sterilis Fruits. Molecules 2016, 21, 1204. [CrossRef] [PubMed]

16. Ashraf, S.A.; Al-Shammari, E.; Hussain, T.; Tajuddin, S.; Panda, B.P. In-vitro antimicrobial activity and identification of bioactive components using GC-MS of commercially available essential oils in Saudi Arabia. J. Food Sci. Technol. 2017, 54, 3948-3958. [CrossRef] [PubMed]

17. Ryu, J.; Lyu, J.I.; Kim, D.-G.; Kim, J.-M.; Jo, Y.D.; Kang, S.-Y.; Kim, J.-B.; Ahn, J.-W.; Kim, S.H. Comparative Analysis of Volatile Compounds of Gamma-Irradiated Mutants of Rose (Rosa hybrida). Plants 2020, 9, 1221. [CrossRef]

18. Thakur, M.; Bhatt, V.; Kumar, R. Effect of shade level and mulch type on growth, yield and essential oil composition of damask rose (Rosa damascena Mill.) under mid hill conditions of Western Himalayas. PLoS ONE 2019, 14, e0214672. [CrossRef] [PubMed] 
19. Kürkçüoglu, M.; Abdel-Megeed, A.; Başer, K. The composition of Taif rose oil. J. Essent. Oil Res. 2013, 25, 364-367. [CrossRef]

20. Venkataraman. 2011. Available online: http://www.alarabiya.net/articles/2011/04/28/146993.html (accessed on 28 April 2011).

21. Hatamian, M.; Arab, M.; Roozban, M.R. Stomatal behavior of two rose cultivar under different light intensities. J. Agric. Crops Prod. 2015, 17, 1-11.

22. Attia, H.; Al-Yasi, H.; Alamer, K.; Ali, E.; Hassan, F.; Elshazly, S.; Hessini, K. Induced anti-oxidation efficiency and others by salt stress in Rosa damascena Miller. Sci. Hortic. 2020, 274, 109681. [CrossRef]

23. Xiao, Z.; Luo, J.; Niu, Y.; Wu, M. Characterization of key aroma compounds from different rose essential oils using gas chromatography-mass spectrometry, gas chromatography-olfactometry and partial least squares regression. Nat. Prod. Res. 2017, 32, 1567-1572. [CrossRef]

24. Datta, S.K. Breeding of New Ornamental Varieties: Rose. Curr. Sci. 2018, 114, 114. [CrossRef]

25. Paul, D. Osmotic stress adaptations in rhizobacteria. J. Basic Microbiol. 2013, 53, 101-110. [CrossRef] [PubMed]

26. Sánchez-Montesinos, B.; Diánez, F.; Moreno-Gavira, A.; Gea, F.J.; Santos, M. Plant Growth Promotion and Biocontrol of Pythium ultimum by Saline Tolerant Trichoderma Isolates under Salinity Stress. Int. J. Environ. Res. Public Health 2019, 16, 2053. [CrossRef] [PubMed]

27. Rahneshan, Z.; Nasibi, F.; Moghadam, A.A. Effects of salinity stress on some growth, physiological, biochemical parameters and nutrients in two pistachio (Pistacia vera L.) rootstocks. J. Plant Interact. 2018, 13, 73-82. [CrossRef]

28. Verma, R.S.; Rahman, L.U.; Verma, R.K.; Chauhan, A.; Singh, A. Essential oil composition of Pelargonium graveolens L'Her ex Ait. cultivars harvested in different seasons. J. Essent. Oil Res. 2013, 25, 372-379. [CrossRef]

29. Boukhris, M.; Bouaziz, M.; Feki, I.; Jemai, H.; El Feki, A.; Sayadi, S. Hypoglycemic and antioxidant effects of leaf essential oil of Pelargonium graveolens L'Hér. in alloxan induced diabetic rats. Lipids Health Dis. 2012, 11, 81. [CrossRef]

30. Koksall, N.; Aslancan, H.; Sadighazadi, S.; Kafkas, E. Chemical investigation on Rose damascena Mill. volatiles; Effects of storage and drying conditions. Acta Sci. Pol. Hortorum Cultus 2015, 14, 14.

31. Sarmoum, R.; Haid, S.; Biche, M.; Djazouli, Z.; Zebib, B.; Merah, O. Effect of Salinity and Water Stress on the Essential Oil Components of Rosemary (Rosmarinus officinalis L.). Agronomy 2019, 9, 214. [CrossRef] 